\section{Original Article}

Check for updates

\section{OPEN ACCESS}

Received: Jul 16, 2019

Revised: Jan 15, 2020

Accepted: Jan 15, 2020

Correspondence to

\section{Mariko Higa}

Division of Diabetes and Endocrinology,

Department of Medicine, Saiseikai

Yokohamashi Tobu Hospital, 3-6-1

Shimosueyoshi, Tsurumi-ku, Yokohama-shi,

Kanagawa 230-0012, Japan.

E-mail: mariko-h@wb3.so-net.ne.jp

Copyright (c) 2020. The Korean Society of Clinical Nutrition

This is an Open Access article distributed under the terms of the Creative Commons Attribution Non-Commercial License (https:// creativecommons.org/licenses/by-nc/4.0/) which permits unrestricted non-commercial use, distribution, and reproduction in any medium, provided the original work is properly cited.

\section{ORCID IDS}

Yukie Fuse (D)

https://orcid.org/0000-0003-4644-9084 Mariko Higa (D)

https://orcid.org/0000-0001-9650-7882 Naoko Miyashita (D)

https://orcid.org/0000-0002-8057-7496

Asami Fujitani (D)

https://orcid.org/0000-0001-8683-3414

Kaoru Yamashita (D)

https://orcid.org/0000-0001-7922-8275

Takamasa Ichijo (D)

https://orcid.org/0000-0002-2969-7396

\title{
Effect of High $\beta$-glucan Barley on Postprandial Blood Glucose and Insulin Levels in Type 2 Diabetic Patients
}

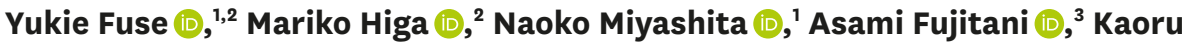 \\ Yamashita $\left({ }^{1},{ }^{2}\right.$ Takamasa Ichijo $\left(\mathbb{D},,^{2}\right.$ Seiichiro Aoe $\left(\mathbb{D},,^{4}\right.$ and Takahisa Hirose $\mathbb{( D}^{1}$
}

'Division of Diabetes, Metabolism, and Endocrinology, Department of Medicine, Toho University Graduate School of Medicine, Tokyo 143-8541, Japan

${ }^{2}$ Department of Diabetes and Endocrinology, Department of Medicine, Saiseikai Yokohamashi Tobu Hospital, Kanagawa 230-0012, Japan

${ }^{3}$ Nutrition Support Team, Saiseikai Yokohamashi Tobu Hospital, Kanagawa 230-0012, Japan

${ }^{4}$ Department of Food Science, Faculty of Home Economics, Otsuma Women's University, Tokyo 102-8357, Japan

\section{ABSTRACT}

The aim of our study was to investigate whether high $\beta$-glucan-containing barley $(7.2 \mathrm{~g}$ per $100 \mathrm{~g}$ ) improves postprandial plasma glucose levels and suppresses postprandial insulin levels during a meal tolerance test in type 2 diabetic patients. A meal tolerance test (500 kcal) was conducted using two types of test meals: a test meal with white rice (WR) alone (WR diet) and a test meal with WR mixed with $50 \%$ barley (BR diet) as staple food. The side dish was the same in the both meals. The changes in plasma glucose and serum C-peptide immunoreactivity (CPR) levels for 180 minutes after ingestion of the test meals were compared. Ten patients with type 2 diabetes (age $52.5 \pm 15.1$ years, and 7 males and 3 females) were included in this study. The mean HbA1c level and body mass index were 8.8 $\pm 1.4 \%$, and $29.7 \pm 4.5 \mathrm{~kg} / \mathrm{m}^{2}$, respectively. Plasma glucose levels after ingestion of the WR diet or BR diet peaked at 60 minutes, which showed no significant differences between the two types of test meals. However, the incremental area under the curve (IAUC) of plasma glucose levels after ingestion of BR diet was significantly lower than that of WR diet. The serum CPR levels at $180 \mathrm{~min}$ and their IAUC over 180 minutes after ingestion of BR diet were significantly lower than those of WR diet. Conclusion: Increase in postprandial plasma glucose and insulin levels was suppressed by mixing high- $\beta$-glucan barley with WR in type 2 diabetic patients.

Keywords: Diet therapy; Beta glucan; Barley; Postprandial hyperglycemia; Type 2 diabetes

\section{INTRODUCTION}

The prevalence of diabetes is increasing worldwide. A total of 425 million adults are living with diabetes, and this estimate is projected to increase to more than 693 million by 2045 [1]. In Japan, the incidence of obesity and glucose intolerance is also increasing [2]. Lifestyle management including nutrition therapy and increased physical activity is important to prevent obesity and diabetes [1,2]. Postprandial hyperglycemia causes hyperinsulinemia and insulin resistance, and these are well known risk factor for obesity, glucose intolerance 
Seiichiro Aoe iD

https://orcid.org/0000-0003-2852-7405

Takahisa Hirose (iD)

https://orcid.org/0000-0001-6293-5010

Funding

The study was supported by the Research Project on Development of Agricultural Products and Food with Health-promoting Benefits awarded by National Agriculture and Food Research Organization (NARO), Japan.

Conflict of Interest

The authors declare that they have no

competing interests. and cardiovascular diseases [3-5]. The amount of carbohydrate primarily contributes to the increase in postprandial plasma glucose level [6-8], and although it is the same carbohydrate, plasma glucose level elevation may vary depending on its quality [9]. The glycemic index (GI) is an indicator of carbohydrate quality which ranks carbohydrates based on the rate of glycemic response [9]. Brown rice and barley have a lower GI value and suppressive effect on postprandial plasma glucose level elevation, because they contain a higher amount of dietary fiber than white rice (WR) [10-12]. Barley contains higher amount of insoluble and soluble dietary fiber, and most of the soluble dietary fiber is $\beta$-glucan $[13,14]$. It has been pointed out that $\beta$-glucan may reduce the risk of cardiovascular diseases through its blood cholesterollowering action and other effects [15].

Asians individuals have traditionally consumed WR as a staple food which is said to constitute a healthy diet, however, it is a high-GI food [9]. High intake of WR causes an increase in postprandial plasma glucose level and is known to be associated with an increased risk of diabetes and metabolic syndrome [16]. A previous study reported that intake of high $\beta$-glucan barley led to reduction in visceral fat [17]. Our previous study showed that high $\beta$-glucan barley suppressed plasma glucose level elevation and oxidant stress after meals in subjects with normal glucose tolerance [18].

We conducted meal tolerance tests using test meal of WR mixed with two-rowed hull-less barley containing higher amounts of $\beta$-glucan ( $7.2 \mathrm{~g}$ per $100 \mathrm{~g}$ ) than common barley [19] in type 2 diabetic patients and examined whether high- $\beta$-glucan barley improves postprandial hyperglycemia and hyperinsulinemia.

\section{MATERIALS AND METHODS}

\section{Study subjects}

Ten patients with type 2 diabetes ( 7 males and 3 females) who were admitted to Saiseikai Yokohamashi Tobu Hospital between January 2015 and August 2015 for diabetic control were recruited. The inclusion criteria were as follows: 1) age was less 75 years old, 2) fasting plasma glucose levels were $140 \mathrm{mg} / \mathrm{dL}$ or less, 3) daily plasma glucose level fluctuations were less 100 $\mathrm{mg} / \mathrm{dL}, 4)$ treatment with oral hypoglycemic agents with or without insulin injection. Patients with severe renal dysfunction (estimated glomerular filtration rate less than $50 \mathrm{~mL} / \mathrm{min} / 1.73$ $\mathrm{m}^{2}$ ) were excluded. A dietary survey confirmed that the patients included in this study did not eat food containing barley for a week prior to the study. The mean age of the subjects was 52.5 \pm 15.1 years. The mean body mass index and, fasting plasma glucose and HbA1c levels were $29.7 \pm 4.5 \mathrm{~kg} / \mathrm{m}^{2}, 103.3 \pm 11.4 \mathrm{mg} / \mathrm{dL}$, and $8.8 \pm 1.4 \%$, respectively. In regard to the treatment of diabetes, 4 patients were receiving insulin with oral hypoglycemic agents, and 6 patients were receiving oral hypoglycemic agents alone. Of the 10 patients treated with insulin or oral hypoglycemic agents, one was receiving pioglitazone, 6 were receiving incretin related drugs (3 using dipeptidyl peptidase-4 [DPP-4] inhibitor and 3 using glucagon-like peptide-1 [GLP-1] receptor agonist), and 6 were receiving metformin. The treatment of the patients, including oral antidiabetic agents, and doses of insulin and GLP-1 receptor agonist, was not changed throughout the study period. The study was conducted according to the guidelines of the Declaration of Helsinki and all procedures were approved by the ethics committee of the Saiseikai Yokohamashi Tobu Hospital (file number 2013030). Written informed consent was obtained from all patients. 


\section{Meal tolerance test}

The patients fasted after 21:00 on the day before the test and ingested a test meal adjusted to approximately $500 \mathrm{kcal}$ in the early morning. The meal tolerance test was conducted for 2 consecutive days. Two types of diets were prepared: one consisted of WR only as staple food and a side dish (WR diet), and the other consisted of WR mixed with $50 \% \beta$-glucan rich barley (BR) as staple food and the same side dish as that in the WR diet (BR diet). The barley used in this study is "Kirarimochi," which was registered as a new breed of two-rowed hull-less barley in 2009 and contains a high amount of $\beta$-glucan (7.2 g per $100 \mathrm{~g}$ ) [19]. It was developed by the National Agriculture and Food Research Organization in Japan. The $\beta$-glucan content of normal covered barleys is about $4 \%$, whereas Kirarimoch has $\beta$-glucan contents of $5.8 \%$. This barley line is not a genetically modified crop. The high- $\beta$-glucan barley was pearled to remove the bran (pearled to $60 \%$ yield) and the remaining $60 \%$ was used as rice-shaped barley [19]. The BR diet consisted of $50 \%$ high- $\beta$-glucan rice-shaped barley (Kirarimochi) and 50\% WR. The test meal was ingested for approximately 15 minutes. This study was conducted with randomized cross-over design, and the subjects were divided into two groups. The meal of the first day was assigned as WR or BR in the sequential order of group registration. Each group ingested the WR or BR diet on the first day and switched to the other type the following day. The WR diet contained $504 \mathrm{kcal}, 80 \mathrm{~g}$ of carbohydrate (glucose $76.9 \mathrm{~g}$, dietary fiber $3.5 \mathrm{~g}$ ), $18.7 \mathrm{~g}$ protein, and $11.4 \mathrm{~g}$ lipid, while the BR diet contained $479 \mathrm{kcal}, 75 \mathrm{~g}$ carbohydrate (glucose $68.8 \mathrm{~g}$, dietary fiber $6.3 \mathrm{~g}$ ), $18.9 \mathrm{~g}$ protein and $11.6 \mathrm{~g}$ lipid. The amount of staple food was adjusted to $150 \mathrm{~g}$ for both WR and BR diets.

Plasma glucose level was measured before and 30, 60, 120, and 180 minutes after ingestion of the WR or BR diet. Serum C-peptide immunoreactivity (CPR), and plasma triglyceride and free fatty acid (FFA) levels were measured before ingestion and 60 and 180 minutes after ingestion. Serum CPR levels were measured by electro chemiluminescence immunoassay methods (BML, Tokyo, Japan). Plasma triglyceride and FFA levels were measured using enzymatic methods (BML). The incremental area under the curve (IAUC) of plasma glucose and serum CPR levels was calculated using the trapezoidal method [20] from the values of up to 180 minutes after ingestion, with the value at fasting state as baseline.

\section{Statistical analysis}

The results are expressed as mean \pm standard deviation. Temporal changes in plasma glucose, triglyceride and FFA, and serum CPR levels from the fasting state up to 180 minutes after ingestion were evaluated by paired Student's t-tests. When the variables did not exhibit a normal distribution, the variables were subjected to the Wilcoxon's-rank sum test to compare two groups. The differences between the changes in WR and BR diet were evaluated by unpaired Student's t-tests, and Welch's t-tests were employed for analysis if equal variance was not assumed. Unpaired t-tests were used to compare the IAUC of plasma glucose and serum CPR levels between WR and BR diet. In this study, the difference was regarded as significant if the $\mathrm{p}$-value was $<0.05$ in a two-sided test. Statistical software SAS JMP version 11 (SAS Institute Inc., Cary, NC, USA) was used for statistical analysis.

\section{RESULTS}

Plasma glucose levels before ingestion of the WR diet was $103.3 \pm 11.4 \mathrm{mg} / \mathrm{dL}$, significantly increased to $169.5 \pm 38.4 \mathrm{mg} / \mathrm{dL}$ at 60 minutes after ingestion ( $\mathrm{p}<0.001)$, which was the peak value, and returned to $137.3 \pm 33.5 \mathrm{mg} / \mathrm{dL}$ at 180 minutes after ingestion. After ingestion of the BR diet, blood glucose levels significantly increased from $109.7 \pm 14.0 \mathrm{mg} / \mathrm{dL}$ to $169.4 \pm$ $24.3 \mathrm{mg} / \mathrm{dL}$ at 60 minutes after ingestion ( $\mathrm{p}<0.001)$, which was the peak value, and returned 
to $133.6 \pm 25.8 \mathrm{mg} / \mathrm{dL}$ at 180 minutes after ingestion. No significant differences in plasma glucose levels were seen between WR and BR diet, while blood glucose levels at 120 minutes after ingestion of the BR diet were tented to be lower compared to those of the WR diet (149.8 $\pm 26.3 \mathrm{mg} / \mathrm{dL}$ vs. $162.2 \pm 30.8 \mathrm{mg} / \mathrm{dL}, \mathrm{p}<0.051$ ) (Figure 1). The IAUC of plasma glucose levels over 180 minutes after ingestion of the WR diet was 4,468.5 $\pm 1,958.4 \mathrm{mg} \cdot \mathrm{min} / \mathrm{dL}$, whereas it was $3,345.0 \pm 1,473.5 \mathrm{mg} \cdot \mathrm{min} / \mathrm{dL}$ after ingestion of the BR diet, which was a significantly lower value compared to those of WR $\operatorname{diet}(\mathrm{p}<0.05)$ (Figure 2).

The serum CPR levels significantly increased from $2.51 \pm 1.61 \mathrm{ng} / \mathrm{mL}$ to $7.46 \pm 4.94 \mathrm{ng} / \mathrm{mL}$ at 180 minutes after ingestion of WR diet ( $<<0.001$ ), while they increased from $2.47 \pm 1.55 \mathrm{ng}$ / $\mathrm{mL}$ to $6.05 \pm 3.18 \mathrm{ng} / \mathrm{mL}$ after ingestion of BR diet $(\mathrm{p}<0.001)$. The serum CPR levels at 180 minutes after ingestion of the BR diet were significantly lower than those of the WR diet $(\mathrm{p}<$ 0.05) (Table 1). The IAUC of serum CPR levels over 180 minutes after ingestion of the BR diet were significant lower compared those of the WR diet $(153.6 \pm 89.4 \mathrm{ng} / \mathrm{mL}$ vs. $233.7 \pm 191.5$ $\mathrm{ng} / \mathrm{mL}, \mathrm{p}<0.05$ ) (Figure 3 ). In the 6 patients treated with incretin related drugs, the IAUC of

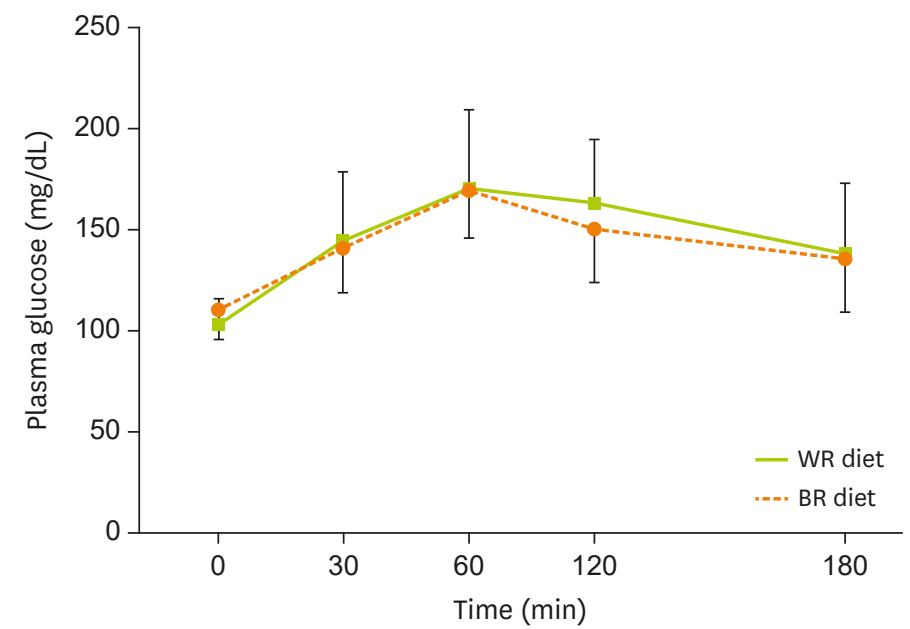

Figure 1. Changes in plasma glucose levels after the consumption of test meals with WR diet or BR diet. WR diet, white rice alone; BR diet, white rice mixed with $50 \% \beta$-glucan rich barley.

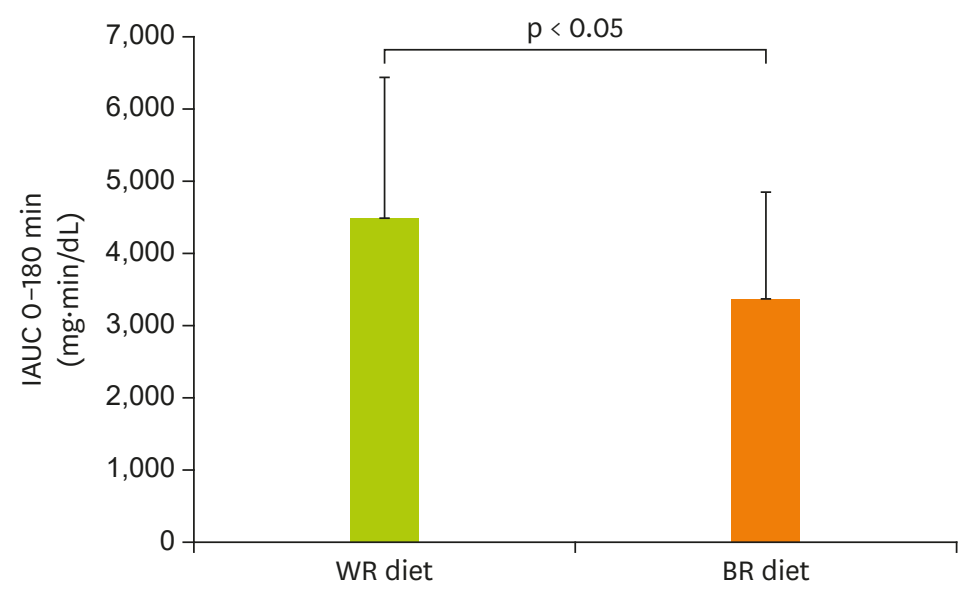

Figure 2. The IAUC of plasma glucose over 180 minutes after the consumption of test meals with WR diet or BR diet. IAUC, incremental area under the curve; WR diet, white rice alone; BR diet, white rice mixed with $50 \% \beta$-glucan rich barley. 
Table 1. Changes in serum CPR levels after the consumption of test meals with WR diet or BR diet

\begin{tabular}{lcccc}
\hline Variables & 0 min & $60 \min$ & 180 min & $p$ value \\
\hline WR diet serum CPR $(\mathrm{ng} / \mathrm{mL})$ & $2.51 \pm 1.61$ & $5.02 \pm 2.73^{*}$ & $7.46 \pm 4.94^{*}$ & \\
BR diet serum CPR $(\mathrm{ng} / \mathrm{mL})$ & $2.47 \pm 1.55$ & $5.63 \pm 3.64^{*}$ & $6.05 \pm 3.18^{*}$ & ]+
\end{tabular}

Data are presented as mean \pm standard deviation.

CPR, C-peptide immunoreactivity; WR diet, white rice as staple food; BR diet, white rice mixed with $50 \%$ $\beta$-glucan rich barley as staple food.

${ }^{*} p<0.001$, before vs. after meal ${ }^{\dagger} p<0.05$, white rice diet vs. barley diet.

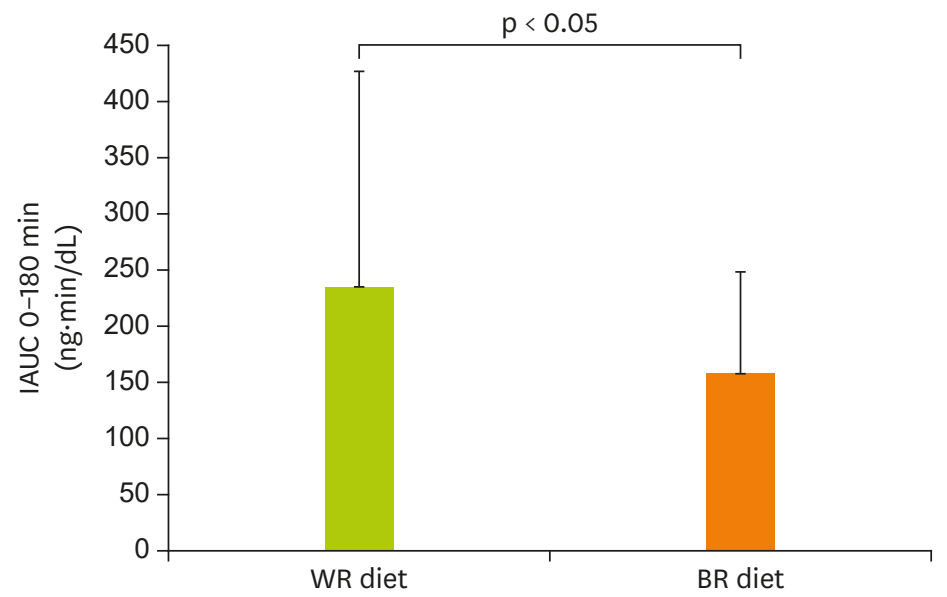

Figure 3. The IAUC of serum C-peptide immunoreactivity over 180 minutes after the consumption of test meals with WR diet or BR diet.

IAUC, incremental area under the curve; WR diet, white rice alone; BR diet, white rice mixed with $50 \% \beta$-glucan rich barley.

serum CPR levels over 180 minutes after ingestion of WR diet were tented to be higher than those in the 4 patients not receiving incretin related drugs $(282.0 \pm 225.6 \mathrm{ng} / \mathrm{mL}$ vs. $161.3 \pm$ $116.2 \mathrm{ng} / \mathrm{mL}$ ). Furthermore, the difference of the IAUC of serum CPR levels over 180 minutes between WR diet and BR diet in the 6 patients receiving incretin related drugs was tented to be higher than that in the 4 patients not receiving incretin related drugs. No significant differences were seen in the IAUC of serum CPR levels over 180 minutes between the patients receiving and those not receiving metformin.

Blood triglyceride levels significantly increased from the base values to 180 minutes after ingestion of the WR and BR diets ( $\mathrm{p}<0.001)$. However, there was no significant difference between the WR and BR diets. Furthermore, the increase in blood triglyceride levels after ingestion of the WR and BR diets showed no significant difference due to blood triglyceride levels prior to ingestion. The FFA level at 180 minutes after ingestion significantly decreased compared with that before ingestion, but no significant differences were seen between the two groups (Table 2).

Table 2. Changes in plasma lipid levels after the consumption of test meals with WR diet or BR diet

\begin{tabular}{lcccc}
\hline Variables & Meal tolerance test & 0 min & $60 \mathrm{~min}$ & $180 \mathrm{~min}$ \\
\hline Triglyceride $(\mathrm{mg} / \mathrm{dL})$ & WR diet & $116.0 \pm 39.2$ & $120.2 \pm 34.8$ & $143.6 \pm 44.8^{*}$ \\
& BR diet & $120.7 \pm 30.6$ & $121.8 \pm 29.1$ & $149.3 \pm 49.7^{*}$ \\
Free fatty acid (mEq/L) & WR diet & $0.58 \pm 0.20$ & $0.42 \pm 0.18^{*}$ & $0.29 \pm 0.12^{*}$ \\
& BR diet & $0.57 \pm 0.15$ & $0.44 \pm 0.19$ & $0.32 \pm 0.15^{\dagger}$ \\
\hline
\end{tabular}

Data are presented as mean \pm standard deviation.

WR diet, white rice as staple food; BR diet, white rice mixed with $50 \% \beta$-glucan rich barley as staple food.

${ }^{*} \mathrm{p}<0.01 ;{ }^{\dagger} \mathrm{p}<0.001$, before vs. after meal. 


\section{DISCUSSION}

We previously reported that postprandial glucose level elevation and glucose level fluctuation were suppressed by ingestion of a mix of high- $\beta$-glucan barley and WR in subjects with normal glucose tolerance using a meal tolerance test and continuous glucose monitoring (CGM) system [18]. The present study indicated that the IAUC of blood glucose levels over 180 minutes after ingestion of the meal with a mix of high- $\beta$-glucan barley and WR was significantly lower than that of the meal with WR alone. Moreover, the CPR levels after ingestion significantly decreased in the meal with a mix of high- $\beta$-glucan barley with WR in type 2 diabetic patients. This study showed that high- $\beta$-glucan barley might be useful in ameliorating postprandial hyperglycemia in not only healthy subjects but also patients with type 2 diabetes. Dietary fiber is divided into water -soluble and insoluble dietary fiber [13,14]. Insoluble dietary fiber improves bowel movement by increasing the volume of stools [21]. In contrast, soluble dietary fiber, which is mixed with food inside the intestine, suppresses acute glucose and serum cholesterol level elevation due to its slow movement within the intestine $[22,23]$. Soluble dietary fibers, especially $\beta$-glucan, strongly delay the digestion and absorption of nutrients due to their high viscosity [24]. $\beta$-glucan accounts for a large part of the soluble dietary fiber of barley, and even pearled and rolled barley contains more than 19 times more dietary fiber than polished rice, which may indicate that the content of $\beta$-glucan in barley is higher than that in other grains $[24,25]$. Conventionally, the content of $\beta$-glucan in barley is reported to be $4.7 \mathrm{~g}$ per $100 \mathrm{~g}$, but the content of $\beta$-glucan in the Kirarimochi barley used in this study was as high as $7.2 \mathrm{~g}$ per $100 \mathrm{~g}$ [19].

Some studies reported that ingestion of glutinous brown rice ameliorated postprandial glucose excursion and insulin hypersecretion with intake of WR [12]. Glutinous brown rice contains gamma-oryzanol, which may improve metabolic parameters $[12,26]$. The effects of $\beta$-glucan in barley including delayed digestion and absorption and delayed gastric emptying may contribute to the suppression of acute glucose level elevation after ingestion $[22,23]$. There is a possibility that addition of barley or similar cereals to rice, a high GI food, may lower the GI and treat postprandial hyperglycemia. The finding that mixing barley with WR improves postprandial blood glucose levels may lead to prevention of diabetes and metabolic syndrome $[27,28]$. High- $\beta$-glucan barley decreases postprandial insulin hypersecretion, which may contribute to further prevention of obesity and metabolic syndrome and improvement of insulin sensitivity with prolonged ingestion [29]. It has recently been shown that fermentable fiber prevents metabolic syndrome by nourishing the microbiota [30]. It is also reported that meals including vegetables and dietary fiber increase GLP-1 compared with meals with WR alone and suppress hyperglycemia and excessive secretion of endogenous insulin after meals [31]. The previous study reported significant differences in the effects of glutinous brown rice between patients treated with and those not treated with DPP-4 inhibitors [12]. A possible explanation is that glutinous brown rice might stimulate GLP-1 secretion secondary to increased production of short-chain fatty acids from dietary fiber by the gut microbial flora $[30,31]$. In this study, patients receiving incretin-related drugs showed a tendency towards decreased insulin secretion by mixing high- $\beta$-glucan barley with WR compared to patients not receiving incretin-related drugs, through the increase in GLP-1 levels. There were some limitations to this study. First, the number of subjects was small and the width of age range was wide, so the results cannot be generalized to the total population and all gender of patients with type 2 diabetes. Second, the patients studied used various types of oral hypoglycemic agents. 
Soluble dietary fiber has a serum cholesterol and triglyceride-lowering effect and improves intrahepatic lipid accumulation [32]. The barely-mediated increase in fecal bile acid excretion enhances the metabolism of cholesterol to bile acid in the liver and decreases blood cholesterol levels as a result of the decrease in liver cholesterol levels [33]. In this study, there were no changes in serum triglyceride and FFA levels between the BR and WR diet.

In conclusion, in the meal tolerance test, IAUC for glucose and CPR levels over 180 minutes after ingestion significantly decreased by the consumption of WR mixed with 50\% high $\beta$-glucan barley in type 2 diabetic patients. We suggest that lowering the GI of WR or $\beta$-glucan per se suppressed postprandial hyperglycemia and excessive insulin secretion. It might contribute to prevention of obesity and suppress the onset of diabetes vascular disease in Asian patients with diabetes who use WR as a staple food. However, further long-term research is needed to clarify whether high- $\beta$-glucan barley improves postprandial blood glucose levels and insulin resistance. Furthermore, a limitation of this study is that the number of subjects is small and width of age range is wide.

\section{REFERENCES}

1. International Diabetes Federation. IDF diabetes atlas-8th edition. Available from https://www. diabetesatlas.org [cited 2019 June 15]. 2019.

2. Mukai N, Doi Y, Ninomiya T, Hirakawa Y, Nagata M, Yoshida D, Hata J, Fukuhara M, Nakamura U, Kitazono T, Kiyohara Y. Trends in the prevalence of type 2 diabetes and prediabetes in communitydwelling Japanese subjects: The Hisayama Study. J Diabetes Investig 2014;5:162-9. PUBMED | CROSSREF

3. DeFronzo RA, Ferrannini E. Insulin resistance. A multifaceted syndrome responsible for NIDDM, obesity, hypertension, dyslipidemia, and atherosclerotic cardiovascular disease. Diabetes Care 1991;14:173-94. PUBMED | CROSSREF

4. Katakami N. Mechanism of development of atherosclerosis and cardiovascular disease in diabetes mellitus. J Atheroscler Thromb 2018;25:27-39. PUBMED | CROSSREF

5. Kato M, Noda M, Mizoue T, Goto A, Takahashi Y, Matsushita Y, Nanri A, Iso H, Inoue M, Sawada N, Tsugane S; JPHC Study Group. Diagnosed diabetes and premature death among middle-aged Japanese: results from a large-scale population-based cohort study in Japan (JPHC study). BMJ Open 2015;5:e007736. PUBMED | CROSSREF

6. Silva FM, Kramer CK, Crispim D, Azevedo MJ. A high-glycemic index, low-fiber breakfast affects the postprandial plasma glucose, insulin, and ghrelin responses of patients with type 2 diabetes in a randomized clinical trial. J Nutr 2015;145:736-41. PUBMED | CROSSREF

7. Soong YY, Quek RY, Henry CJ. Glycemic potency of muffins made with wheat, rice, corn, oat and barley flours: a comparative study between in vivo and in vitro. Eur J Nutr 2015;54:1281-5. PUBMED | CROSSREF

8. Truswell AS. Glycaemic index of foods. Eur J Clin Nutr 1992;46 Suppl 2:S91-101. PUBMED

9. Brouns F, Bjorck I, Frayn KN, Gibbs AL, Lang V, Slama G, Wolever TM. Glycaemic index methodology. Nutr Res Rev 2005;18:145-71. PUBMED | CROSSREF

10. Bui TN, Le TH, Nguyen H, Tran QB, Nguyen TL, Le DT, Nguyen VA, Vu AL, Aoto H, Okuhara Y, Ito Y, Yamamoto S, Kise M. Pre-germinated brown rice reduced both blood glucose concentration and body weight in Vietnamese women with impaired glucose tolerance. J Nutr Sci Vitaminol (Tokyo) 2014;60:183-7. PUBMED | CROSSREF

11. Cândido FG, Ton WT, Alfenas RC. Addition of dietary fiber sources to shakes reduces postprandial glycemia and alter food intake. Nutr Hosp 2015;31:299-306. 
12. Nakayama T, Nagai Y, Uehara Y, Nakamura Y, Ishii S, Kato H, Tanaka Y. Eating glutinous brown rice twice a day for 8 weeks improves glycemic control in Japanese patients with diabetes mellitus. Nutr Diabetes 2017;7:e273. PUBMED | CROSSREF

13. Grundy MM, Quint J, Rieder A, Ballance S, Dreiss CA, Cross KL, Gray R, Bajka BH, Butterworth PJ, Ellis PR, Wilde PJ. The impact of oat structure and $\beta$-glucan on in vitro lipid digestion. J Funct Foods 2017;38:378-88. PUBMED | CROSSREF

14. Oda T, Aoe S, Sanada H, Ayano Y. Effects of soluble and insoluble fiber preparations isolated from oat, barley, and wheat on liver cholesterol accumulation in cholesterol-fed rats. J Nutr Sci Vitaminol (Tokyo) 1993;39:73-9. PUBMED | CROSSREF

15. EFSA Panel on Dietetic Products. Scientific opinion on the substantiation of a health claim related to barley beta-glucans and lowering of blood cholesterol and reduced risk of (coronary) heart disease pursuant to article 14 of regulation (EC) NO 1924/2006. EFSA J 2011;9:2470. CROSSREF

16. Ley SH, Hamdy O, Mohan V, Hu FB. Prevention and management of type 2 diabetes: dietary components and nutritional strategies. Lancet 2014;383:1999-2007. PUBMED | CROSSREF

17. Aoe S, Ichinose Y, Kohyama N, Komae K, Takahashi A, Abe D, Yoshioka T, Yanagisawa T. Effects of high $\beta$-glucan barley on visceral fat obesity in Japanese individuals: a randomized, double-blind study. Nutrition 2017;42:1-6. PUBMED | CROSSREF

18. Higa M, Fuse Y, Miyashita N, Fujitani A, Yamashita K, Ichijo T, Aoe S, Hirose T. Effect of high $\beta$-glucan barley on postprandial blood glucose levels in subjects with normal glucose tolerance: assessment by meal tolerance test and continuous glucose monitoring system. Clin Nutr Res 2019;8:55-63. PUBMED | CROSSREF

19. Yanagisawa T, Nagamine T, Takahashi A, Takayama T, Doi Y, Matsunaka H, Fujita M. Breeding of Kirarimochi: a new two-rowed waxy hull-less barley cultivar with superior quality characteristics. Breed Sci 2011;61:307-10. CROSSREF

20. Wilkins PA, Sheahan BJ, Vander Werf KA, Castagnetti C, Hardy J, Schoster A, Boston RC. Preliminary investigation of the area under the L-lactate concentration-time curve (LACArea) in critically ill equine neonates. J Vet Intern Med 2015;29:659-62. PUBMED | CROSSREF

21. Saito T, Hayakawa T, Nakamura K, Takita T, Suzuki K, Innami S. Fecal output, gastrointestinal transit time, frequency of evacuation and apparent excretion rate of dietary fiber in young men given diets containing different levels of dietary fiber. J Nutr Sci Vitaminol (Tokyo) 1991;37:493-508. PUBMED | CROSSREF

22. Wang Q, Ellis PR. Oat $\beta$-glucan: physico-chemical characteristics in relation to its blood-glucose and cholesterol-lowering properties. Br J Nutr 2014;112 Suppl 2:S4-13. PUBMED | CROSSREF

23. Yu K, Ke MY, Li WH, Zhang SQ, Fang XC. The impact of soluble dietary fibre on gastric emptying, postprandial blood glucose and insulin in patients with type 2 diabetes. Asia Pac J Clin Nutr 2014;23:210-8. PUBMED

24. Tosh SM. Review of human studies investigating the post-prandial blood-glucose lowering ability of oat and barley food products. Eur J Clin Nutr 2013;67:310-7. PUBMED | CROSSREF

25. Chandalia M, Garg A, Lutjohann D, von Bergmann K, Grundy SM, Brinkley LJ. Beneficial effects of high dietary fiber intake in patients with type 2 diabetes mellitus. N Engl J Med 2000;342:1392-8. PUBMED | CROSSREF

26. Kozuka C, Yabiku K, Takayama C, Matsushita M, Shimabukuro M, Masuzaki H. Natural food science based novel approach toward prevention and treatment of obesity and type 2 diabetes: recent studies on brown rice and $\gamma$-oryzanol. Obes Res Clin Pract 2013;7:e165-72. PUBMED | CROSSREF

27. Galisteo M, Duarte J, Zarzuelo A. Effects of dietary fibers on disturbances clustered in the metabolic syndrome. J Nutr Biochem 2008;19:71-84. PUBMED | CROSSREF 
28. Aoe S, Ikenaga T, Noguchi H, Kohashi C, Kakumoto K, Kohda N. Effect of cooked white rice with high $\beta$-glucan barley on appetite and energy intake in healthy Japanese subjects: a randomized controlled trial. Plant Foods Hum Nutr 2014;69:325-30. PUBMED | CROSSREF

29. Nolan CJ, Prentki M. Insulin resistance and insulin hypersecretion in the metabolic syndrome and type 2 diabetes: time for a conceptual framework shift. Diab Vasc Dis Res 2019;16:118-27. PUBMED | CROSSREF

30. Zou J, Chassaing B, Singh V, Pellizzon M, Ricci M, Fythe MD, Kumar MV, Gewirtz AT. Fiber-mediated nourishment of gut microbiota protects against diet-induced obesity by restoring IL-22-mediated colonic health. Cell Host Microbe 2018;23:41-53.e4. PUBMED | CROSSREF

31. Kameyama N, Maruyama C, Matsui S, Araki R, Yamada Y, Maruyama T. Effects of consumption of main and side dishes with white rice on postprandial glucose, insulin, glucose-dependent insulinotropic polypeptide and glucagon-like peptide-1 responses in healthy Japanese men. Br J Nutr 2014;111:1632-40. PUBMED | CROSSREF

32. Brockman DA, Chen X, Gallaher DD. Consumption of a high $\beta$-glucan barley flour improves glucose control and fatty liver and increases muscle acylcarnitines in the Zucker diabetic fatty rat. Eur J Nutr 2013;52:1743-53.

PUBMED | CROSSREF

33. Oda T, Aoe S, Imanishi S, Kanazawa Y, Sanada H, Ayano Y. Effects of dietary oat, barley, and guar gums on serum and liver lipid concentrations in diet-induced hypertriglyceridemic rats. J Nutr Sci Vitaminol (Tokyo) 1994;40:213-7.

PUBMED | CROSSREF 